\title{
VIDEOGRAFIA
}

A AUTORA

Maria Ignês Carlos Magno

Doutora em Ciências da Comunicação pela ECA/USP. Professora do curso de Pedagogia do Centro Universitário de São Paulo - UNISAL e da Universidade Anhembi Morumbi. E-mail: unsig@globo.com

\section{UM OLHAR DIFERENTE}

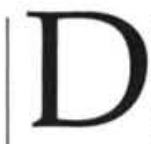
esde o final de setembro de 2001 as matérias de capa das principais revistas e as manchetes dos jornais trazem como destaque a

Guerra ao terror. Qual guerra? Qual terror? São algumas perguntas que podemos fazer. A guerra iniciada por Reagan? Do pai Bush e/ou do filho? Dos países e povos Orientais? Das religiões? Do vitorioso Ocidente industrial capitalista e do milenar pouco desenvolvido (tecnologicamente) Oriente? A guerra fratricida? Das indústrias de armamentos e das indústrias químico-biológico-farmacêuticas? Da disputa pelo domínio geopolítico do Oriente petrolífero? Da mídia? Das imagens televisivas que no fundo são sempre as mesmas, porque a fonte é dominada por uma agência de informações? Diante do bombardeio de imagens dos noticiários de TV e jornais tentando construir discursos homogêneos perante tamanha complexidade histórica - são muitas as perguntas a serem feitas. Imagens e discursos que ao tentarem justificar ataques terroristas, bombardeios e retaliações mostram-nos povos supostamente pouco civilizados, porque não têm as mesmas palavras e personagens que compõem o nosso repertório. Povos e histórias que, acima de tudo, despertam nossa curiosidade não apenas porque nos são mostrados como exóticos, mas pela sua realidade cotidiana.

$\mathrm{Na}$ verdade, o espelho do mundo ocidental, ao se quebrar e se mostrar tão frágil como qualquer espelho, possibilita-nos que, ao recolhermos os cacos, possamos olhar e enxergar outros mundos, outros povos e culturas com mais cuidado. Ou ainda, e esse será um dos objetivos dessa Videografia, que possamos pesquisar as histórias que nos eram distantes e particulares (estavam longe) e compreender muitos fatos e alianças que extrapolam em tempo e histórias o que os noticiários nos trazem. O outro objetivo é o de conhecer histórias de povos que possuem cores, sons, visões de mundo, de pessoas, de edu- 
cação e de arte muito refinados, fazendonos entender porque as culturas são plurais, únicas e universais ao mesmo tempo e, principalmente, porque a realidade histórica não pode ser simplificada ou reduzida às manchetes de jornais, noticiários de TV ou capas de revistas do Ocidente ou do Oriente. Relembrando Lenine quando se referia à complexidade histórica: "o verde das árvores é muito mais verde do que parece".

Como o objetivo é duplo e a idéia é sempre a de buscar na complexidade a compreensão e ampliação de nossos conhecimentos, pensei em quatro filmes que não enfocam a guerra convencional ou terrorista, mas que mostram outros conflitos, lutas, solidariedade, tradições, afetos, arte. A escola e a sala de aula são os fios condutores dos três primeiros filmes e o quarto foi pensado como um dos exemplos de como, através da música e da arte cinematográfica, Ocidente e Oriente se fundiram de forma absurdamente linda. Os filmes são: Quando tudo começa, de Bertrand Tavernier; Onde fica a casa do meu amigo?, de Abbas Kiarostami; O caminho para casa, de Zhang Yimou e $O$ silêncio, de Mohsen Makhmalbaf.

\section{QUANDO TUDO COMEÇA}

(Ça commence aujourd'hui)

Direção - Bertrand Tavernier

Roteiro - Dominique Sampiero, Tiffany

Tavernier e Bertrand Tavernier

Montagem - Sophie Brunet

Fotografia - Alain Choquart

Música - Louis Sclavis

Produção - França

Ano - 1999

Duração - 117 min.

Locadoras comerciais
De acordo com a sinopse, Bertrand Tavernier realizou o seu filme a partir de histórias reais contadas por professores primários. Com um roteiro e câmara semidocumentais, o autor realiza um drama sobre educação infantil. Conta a história de Daniel Lefreve, professor de um escola pública em Hernaing, uma pequena cidade do interior da França, que sofre um alto índice de desemprego. Daniel e os outros professores são aconselhados a não se envolverem com os problemas crônicos da comunidade, mas é impossível para Daniel permanecer imune à miséria, à falta de assistentes sociais, à indiferença do governo e dos sérios problemas domésticos que suas crianças enfrentam. Ainda, de acordo com a sinopse, Quando tudo começa é o retrato de uma nova França em busca de novos caminhos e convivências.

Como drama que relata a luta de um professor/diretor e seus professores numa escola de educação infantil, é um filme que pode ser visto, discutido e analisado pelo corpo docente da escola, na disciplina de Educação infantil dos cursos de Pedagogia, e talvez possa interessar para o terceiro ano do Ensino Médio, momento de escolha das carreiras universitárias. Além do tema em si, penso que o filme é uma boa oportunidade para percebermos que muitos dos problemas que sentimos no nosso cotidiano não se restringem à realidade brasileira, mas afetam todo o sistema de ensino ocidental. Digo ocidental porque desconhecemos ou conhecemos pouco a situação do ensino em outras partes do mundo. E esse pode ser um outro tema a ser buscado e discutido por nós professores: exemplos de outros sistemas de ensino, de outras partes do mundo. Como são as escolas de outras partes do mundo? 
Quais os princípios pedagógicos que as estruturam? Que relações possuem com as suas realidades? Quem são os teóricos? São os mesmos que os nossos? Outros aspectos do filme que podem colaborar para o ensino infantil são os apresentados nas aulas de Daniel, os estímulos, a composição das classes e a quadra, o sentido do pátio para a convivência e fonte de observações.

\section{ONDE FICA A CASA DO \\ MEU AMIGO?}

(Khanen-ye Dust Kojast?)

Direção/Roteiro/Montagem - Abbas

Kiarostami

Fotografia - Farah Saba

Produtor - Alizera Zarrin (Centro para o Desenvolvimento Intelectual de Crianças e Jovens)

País - Irã

Ano - 1987

Duração - 98 min.

Locadoras comerciais

O texto resumo nos conta que, ao fazer o seu dever de casa, Ahmad descobre que pegou o caderno do seu amigo por engano. Sabendo que o professor exige que as tarefas sejam feitas no caderno, ele vai à vila vizinha com o intuito de devolver o caderno. Ahmad não consegue encontrar seu amigo pois não sabe onde ele mora. Ahmad decide, então, voltar para casa e fazer a lição de casa do amigo.

Enquanto Quando tudo começa é um filme ideal para professores e estudantes de pedagogia, Onde fica a casa do meu amigo? pode ser trabalhado por professores e classes a partir da terceira ou quarta séries do Ensino Fundamental, momento em que a alfabetização teoricamente se concretiza e que alguns conceitos e valores podem ser abordados. Para professores, vai como sugestão para conhecer e analisar algumas características de um outro sistema escolar, da função e do lugar do professor, do conceito de disciplina, de autoridade dentro e fora da escola, de respeito mútuo, das condições físicas da escola e da importância da alfabetização e aprendizado apesar de tudo. Para as crianças, uma oportunidade de observar, conversar sobre todos os aspectos que envolvem a educação, a escola, a amizade, $o$ caráter, a determinação e, principalmente, a solidariedade, a responsabilidade, o compromisso e o companheirismo.

A simplicidade da história contada demonstra como é profunda a temática construída pelo cineasta. Dupla profundidade que o cinema de Kiarostami nos apresenta: a dos valores apresentados na história de Ahmad e a dos planos, que ao acompanharem o olhar atento e observador do avô na correria do neto, leva-nos a percorrer o mesmo caminho de Ahmad no desejo de encontrar a casa do amigo e à contemplação da beleza que também reside nesse duplo - o da história e a do cinema.

\section{O CAMINHO PARA CASA}

(The road home)

Direção - Zhang Yimou

Roteiro - Bao Shi

Cenografia-Cao Jiuping

Música - San Bao

Fotografia-Hou Yong

País - China

Ano - 1999

Duração - 86 min.

Produção - Columbia Pictures

Locadoras comerciais

Quando o pai morre, Luo Changyu retorna à cidade de sua infância. Mas a 
curta viagem para o enterro torna-se maior quando descobre que a mãe quer uma cerimônia tradicional para seu amado. Ela deseja que o cortejo seja a pé, honrando a crença de que um corpo que refaz seus passos nunca esquece o caminho para casa.

A sinopse é sempre uma referência inicial. Deixa que nós mesmos descubramos como essa história é construída. Pede que deixemos fluir as leituras que as imagens e os textos sugerem. O primeiro impacto é o da inversão das cores aos olhos acostumados a ver o tempo presente ser contado de forma colorida e as lembranças em branco e preto. No Caminho para casa, as lembranças, a história do amor entre o pai e a mãe de Luo é que são coloridos. $\mathrm{O}$ outro impacto visual é a história que vai sendo tecida pelas mãos da mãe através dos fios do tear que tecem o véu que cobrirá o corpo do pai, uma das tradições da China milenar. Em frente ao quarto onde a mãe trabalha no seu tear, fica o quarto e escritório do pai, professor da aldeia. Luo, sentado na cadeira do pai, observa a mãe e relembra suas histórias. A história de amor de um professor enviado para aquela distante aldeia chinesa e de sua mãe que, apesar do analfabetismo (por opção), sabia de cor todas as lições cantadas para os alunos. Nunca fora à escola, mas ajudou a construí-la junto com todos os habitantes da aldeia e cuidou dela quando o professor voltou para a cidade. Um filme de amores. Amor do professor pela escola, pelos alunos, pelo prazer de ensinar; amor e cuidado dos moradores porque sabiam da importância de ter uma escola e um professor; amor de seus pais; amor pela terra e pelas tradições fundadoras das culturas.

Sugiro o filme como estímulo para estudarmos os povos do extremo Oriente. É um belo filme para recuperarmos tradições culturais e traçarmos paralelos entre culturas e valores, e também como forma de educarmos os nossos olhos para ver outras estéticas e maneiras de fazer cinema.

\section{O SILÊNCIO (Soukut)}

Direção/Roteiro - Mohsen Makhmalbaf

Fotografia - Ebrahim Ghafori

Montagem - Mohsen Makhmalbaf

Som - Behroz Shahamat

Produção - Irã/França

Ano - 1998

Duração - 77 min.

Locadoras comerciais

$O$ silêncio é um filme sobre o som. Os sons de uma vila fronteiriça do Tadjiquistão vão sendo captados por um menino cego (de fato, uma menina) de dez anos. O seu universo é desprovido de imagens mas rico em sons e é por isso que ele se perde todo dia a caminho de seu trabalho, como afinador de instrumentos. O ruído que, no entanto, mais impressiona o menino pobre é o do senhorio batendo na sua porta para cobrar o aluguel. O medo é revertido com originalidade para acordes da Quinta Sinfonia de Bethoven, terminando por ser orquestrada numa sincronia de batidas de meninos, forjando panelas de cobre.

Aqui a sinopse nos diz que $O$ silêncio é um filme sobre o som. Silenciosos é como ficamos ao término do filme. Silêncio é a única sensação que queremos para voltar a respirar e começar a pensar, a rever a história entre coloridos, sons, música, rios, montanhas e uma guerra que se apresentava, no filme, através da hostilidade e tristeza do dono da fábrica de instrumentos e na figura de um soldado-músico. Era apenas uma referência, afinal onde ficava o 
Tadjiquistão? Hoje sabemos que é uma região da Ásia Central, fronteiriça do Afeganistão e que provavelmente servirá de base para uma guerra que já não é só referência.

Este filme nos permite elaborar pesquisas históricas, musicais e artísticas; desenvolver um trabalho interdisciplinar entre história, geografia, música, artes plásticas e entender a síntese que a arte (seja ela cinematográfica ou não) é capaz de fazer no momento em que reelabora e recria a vida em produto estético. Particularmente, desafia-nos a ver e estudar com muita atenção o cinema produzido por esse diretor iraniano: Mohsen Makhmalbaf.

Retornando à parte inicial do texto, quando disse que palavras e personagens antes desconhecidos hoje fazem parte de nosso confuso vocabulário, penso que uma das primeiras histórias que devemos recuperar é a origem do chamado Oriente Médio. Irã, Iraque, Arábia Saudita, Iêmen, Kuwait, Omã, Emirados Árabes Unidos, Barein, Catar, Jordânia, Israel, Síria, Líbia e Afeganistão compõem hoje o chamado Oriente Médio. No entanto, até o final da Primeira Guerra Mundial, faziam parte do Império Turco-Otomano. Com o desmantelamento do Império, desde 1920, potências européias como França e Inglaterra se apossaram desses territórios ricos em petróleo. Em 1924, sob a liderança de Kemal Ataturk, o "pai dos turcos", os povos do Oriente Médio, como parte de um projeto de modernização autoritária, foram obrigados a adotar o alfabeto latino, impedidos de usar barbas e véus, entre outras proibições.

Órfãos de um Império, a constatação de uma derrota histórica e o desejo de encontrar uma solução autêntica incluíram no projeto desses povos a retomada dos laços do passado. De acordo com François Massoulié1, "alguns historiadores pensam que não é exagero afirmar que o islamismo é um movimento modernista, verdadeiro fruto da civilização européia". Para esse autor, "o islamismo político não passa de uma resposta à decadência e ao esfacelamento do império Otomano e ao desejo da 'Renascença Árabe', o que levou um grupo de intelectuais e pensadores a se dedicarem a renovar a língua e a cultura árabes para fazer delas um instrumento de comunicação e de progresso por meio do retorno às origens". Origens que também nos confundem quanto às terminologias $\mathrm{e}$ significados como o de saber que nem todo árabe é muçulmano, porque árabe está relacionado ao lugar, ao nascimento e muçulmano é uma denominação religiosa; nem todo muçulmano é fundamentalista, porque esses foram assim chamados desde a divisão entre os sunitas e os xiitas ou alitas que seguem à risca as ordens do Corão. Por esse pequeno trecho podemos ter idéia do universo de pesquisas que podem ser feitas. Mas para entendermos o mundo oriental na atualidade, o terrorismo oriental, o repúdio ao Ocidente (entenda EUA) e os ataques atuais aos EUA, as imediatas adesões da Inglaterra e Alemanha aos bombardeios norte-americanos no Afeganistão; para conseguirmos discutir a chamada guerra contra o terror, o estudo de alguns temas são fundamentais, tais como: a formação do Estado de Israel, os conflitos árabe-israelenses; a Guerra Irã-Iraque; a Guerra do Golfo; a história

1. MASSOULIÉ. F. Os conflitos do Oriente Médio. São Paulo: Ática, 1995. 
dos Palestinos e dos Curdos; os conflitos no Líbano e a Guerra no Afeganistão desde 1973. A tarefa é difícil, mas surpreendente. Vale a pena conhecer todos os lados de uma história que, ao contrário do que imaginamos ou nos é colocado, não é e não pode ser vista e entendida de forma maniqueísta.

No tocante à música, o filme é precioso em todos os sentidos. Podemos conhecer os tipos de instrumentos, a dedicação de um lugarejo à música, a dança que acompanha o afinamento dos instrumentos, os muitos sons que compõem a natureza e a vida, o colorido constante em volta de quem não pode ver, do som do medo que perseguia o menino, traduzido em muitas formas de sons, produzidos pelas batidas dos martelos nas fábricas de panelas. Trabalho infantil. $\mathrm{O}$ ensinamento das notas da Quinta Sinfonia de Bethoven para os meninos trabalhadores. Bethoven ficou surdo e compôs a Quinta Sonfonia, o me-

Resumo: Partindo da indignação, do horror à guerra dita contra o terror, a autora convida o leitor a uma viagem pela sensibilidade delicada e fina dos filmes: Quando tudo começa, de Bertrand Tovernier; Onde fica a casa do meu amigo?, de Abbas Kiarastami; O caminho para casa, de Zhang Yimou, e $O$ silêncio, de Mohsen Makhmalbaf. Verdadeiro exercício, à medida que estes filmes nos desafiam a observar o outro e sua cultura com respeito, a perceber a beleza de outras estéticas que não aquela dominante e homogeneizadora. Exercício também de reflexāo sobre as práticas do educador e o papel da escola. Um convite à indignação a favor da vida, à amizade e à solidariedade.

Palavras-chave: guerra, Ocidente, Oriente, cultura, terror, cinema nino cego visualiza a música de Bethoven e acaba por orquestrá-la aos sons de panelas, numa fábrica que lembra a nave de uma catedral. O filme se chama $O$ silêncio e deixa forte a imagem de um quadro: o detalhe do brinco feito de cereja, das unhas postiças feitas de flores e a dança mágica da menina, enquanto os instrumentos são afinados pelo menino cego.

Sugestões de bibliografia para pesquisa:

AKCELRUD, Isaac. O Oriente Médio. São Paulo: Ática/Edunicamp, 1986.

BRENER, Jayme. O mundo pós-guerra fria. São Paulo: Scipione, 1996. . Jornal do século XX.

São Paulo: Moderna, 1999.

KARNAL, Leandro. Oriente Médio. São Paulo: Scipione, 1993.

OLIC, Nelson Bacic. Oriente Médio uma região de conflitos. São Paulo: Moderna, 1991.

(A different look)

Abstract: Based on the resentment and on the horror of the so-called war against terror, the author invites the reader to make a trip through the delicate and fine sensibility of the movies: Bertrand Tovernier's When everything begins; Abbas Kiarastami's Where is my friend's house?; Zhang Yimou's The path home; and Mohsen Makhmalbaf's Silence. A true exercise, since these movies challenge us to observe other people and their cultures with respect and to notice the beauty there is in other aesthetics, over and beyond the dominant and homogenizing one. It is also an exercise of reflection on the educator's practices and on the role the school has in society. This is an invitation to indignation in favor of life, friendship and solidarity.

Key words: war, the West, the East, culture, terror, cinema 